\title{
Clinicopathological characteristics and prognostic factors of primary pulmonary lymphoma
}

\author{
Huayu He, Fengwei Tan, Qi Xue, Lei Liu, Yue Peng, Guangyu Bai, Moyan Zhang, Shugeng Gao \\ Department of Thoracic Surgery, National Cancer Center/National Clinical Research Center for Cancer/Cancer Hospital, Chinese Academy of \\ Medical Sciences and Peking Union Medical College, Beijing, China \\ Contributions: (I) Conception and design: H He; (II) Administrative support: S Gao; (III) Provision of study materials or patients: H He; (IV) \\ Collection and assembly of data: H He, F Tan, Q Xue, L Liu, Y Peng, G Bai, M Zhang; (V) Data analysis and interpretation: H He; (VI) Manuscript \\ writing: All authors; (VII) Final approval of manuscript: All authors. \\ Correspondence to: Shugeng Gao. Department of Thoracic Surgery, National Cancer Center/National Clinical Research Center for Cancer/Cancer \\ Hospital, Chinese Academy of Medical Sciences and Peking Union Medical College, 17, Panjiayuan Nan Li Road, Beijing 100021, China. \\ Email: gaoshugeng@vip.sina.com.
}

\begin{abstract}
Background: Primary pulmonary lymphoma (PPL) is a rare extranodal lymphoma originating from the lung, accounting for $0.5-1.0 \%$ of primary lung malignant tumors. Previous case reports or cohort studies included a limited sample size; therefore, the understanding of the disease remains inadequate, and clinical data regarding PPL are limited.

Methods: Patients with PPL diagnosed histologically and radiologically between January 2000 and December 2019 at our center were retrospectively analyzed.

Results: In total, 90 consecutive cases were included in this research. Forty-seven $(52.2 \%)$ patients were female, and the median age was 54 years old. Non-Hodgkin's lymphoma (PPNHL) was the most common type of PPL (71/90, 78.9\%), and mucosa-associated lymphoid tissue (MALT) lymphoma was the most common pathological subtype of PPNHL (56.3\%) followed by diffuse large B-cell lymphoma (DLBCL) (32.4\%). Thirty-nine (43.3\%) patients underwent surgical treatment, and the others received chemotherapy alone or combined with radiotherapy. The estimated 5-year overall survival (OS) rates of MALT lymphoma and non-MALT lymphoma were $68.9 \%$ and $65.9 \%$, respectively. Univariate analysis of PPL showed that clinicopathological features that significantly correlated with worse OS were age over 60 years $(\mathrm{P}=0.006<0.05)$, elevated LDH $(\mathrm{P}=0.029<0.05)$ and $\beta 2-\mathrm{MG}(\mathrm{P}=0.048<0.05)$ levels, clinical stage II2E and greater $(\mathrm{P}=0.015<0.05)$, and nonsurgical treatment $(\mathrm{P}=0.046<0.05)$. Age $(\mathrm{P}=0.013<0.05)$ was an independent prognostic factor for the 5 -year OS of patients through multivariate analysis.

Conclusions: Age over 60 years old, elevated LDH and $32-\mathrm{MG}$ levels, clinical stage II2E disease or higher, and nonsurgical treatment were associated with poor prognosis in patients with PPL. Age can be used as a potential independent prognostic factor for PPL.
\end{abstract}

Keywords: Primary pulmonary lymphoma (PPL); clinicopathological characteristics; prognosis; predictors

Submitted Oct 31, 2020. Accepted for publication Dec 24, 2020.

doi: $10.21037 /$ jtd-20-3159

View this article at: http://dx.doi.org/10.21037/jtd-20-3159

\section{Introduction}

Primary pulmonary lymphoma (PPL) is a lymphocytic malignant clonal proliferative disease involving one or both lungs, and there is no extrapulmonary involvement at the time of diagnosis or in the following 3 months (1).
Compared with other extranodal lymphomas, PPL is extremely rare, accounting for less than $1.0 \%$ of Hodgkin's lymphomas (HLs) and non-Hodgkin's lymphomas (NHLs), $3.0-4.0 \%$ of primary extranodal lymphoma and $0.5-1.0 \%$ of primary pulmonary malignant tumors (2-4). The diagnosis 
of PPL is still mainly based on Cordier's diagnostic criteria: imaging examination in one case clearly showed that the tumor involved the lung and bronchus, but there was no hilar or mediastinal lymph node enlargement and no evidence of lymphoma in other parts of the lung and bronchus. There was no history of extrathoracic lymphoma, and there was no sign of extrapulmonary lymphoma three months after onset (5). The diagnosis and classification of pulmonary lymphoma are mainly based on the differences in morphological and immunological characteristics between the lesion cells and normal T-cells and B-cells. Immunohistochemistry (IHC), cytogenetics, flow cytometry and molecular techniques can help to classify lymphoma by displaying the specific immunophenotype, light chain monoclonal and specific molecular characteristics.

PPL includes primary pulmonary HL and NHL (PPHL and PPNHL), of which PPNHL is the most common. Most PPLs are B-cell lymphomas, and most lesions originate from bronchial-associated lymphoid tissue. Mucosa-associated lymphoid tissue (MALT) lymphoma is the most common type, accounting for $58.0-90.0 \%$ of PPLs; it is more common in women and is often associated with autoimmune diseases (6). The second most common type is diffuse large B-cell lymphoma (DLBCL), which accounts for approximately $10 \%$ of PPLs (7) and is commonly found in elderly or immunosuppressed patients $(8,9)$. Other types of PPNHL include follicular lymphoma, mantle cell lymphoma and lymphoplasmacytic lymphoma. However, PPHL is extremely rare. To date, fewer than 70 cases have been reported in the literature $(10,11)$. The existing literature reports that PPL mainly occurs in the elderly, with a median age at diagnosis of 60 years old, and is relatively rare in children (12). Clinical manifestations are usually not clear or are lacking; cough, expectoration, dyspnea, chest pain, fever and other clinical manifestations can occur, some of which have no obvious symptoms; and the clinical manifestations are not specific (13). The imaging manifestations of PPL are varied, including single or multiple nodules or masses with uniform density or patchy highdensity shadows, and without characteristic manifestations; thus, it is easily misdiagnosed (14). At present, pathological diagnosis is mainly made by surgery or biopsy.

According to the literature, there are only a few studies on PPL, and the number of cases is limited. Understanding of this kind of disease, especially among the Asian population, still needs strengthening. Therefore, we retrospectively reviewed the clinicopathological features, treatment and prognosis of PPL patients treated in our center; summarized the experience of diagnosis and treatment; and explored the potential predictors. We present the following article in accordance with the STROBE reporting checklist (available at http://dx.doi. org/10.21037/jtd-20-3159).

\section{Methods}

\section{Patients}

The clinical records of 90 patients with PPL between 2000 and 2019 were retrospectively reviewed. The inclusion criteria of this study were as follows: (I) a diagnosis of extranodal lymphoma confirmed by operation or biopsy; and (II) radiological examination that confirmed PPL according to Cordier's diagnostic criteria. The pathological diagnosis of all patients with PPL was based on light microscopy and IHC. Fluorescence in situ hybridization was used in 11 patients to achieve accurate diagnosis. Patients with the following conditions were excluded from the study: (I) patients diagnosed with secondary pulmonary lymphoma; (II) patients who lacked the necessary clinical information; and (III) patients who were lost to follow-up. Of the 669 patients excluded, 563 were confirmed to have secondary pulmonary lymphoma, 11 lacked complete clinical data, and 5 were lost to follow-up. Ninety patients were ultimately included in our study (Figure 1). The study was conducted in accordance with the Declaration of Helsinki (as revised in 2013). The study protocol was reviewed and approved by the ethics committee of the National Cancer Center/ Cancer Hospital, Chinese Academy of Medical Sciences and Peking Union Medical College (approval number: 20/313-2509). The requirement for informed consent was waived because of the retrospective nature of this study. All patients underwent bone marrow biopsy, neck and abdomen computed tomography (CT) scan or ultrasound, brain magnetic resonance imaging and radionuclide bone imaging to exclude extrathoracic diseases. In addition, some patients underwent positron emission tomography-computed tomography (PET-CT) examination before treatment. The follow-up of patients was obtained through outpatient records or telephone interviews. The last follow-up time was May 21, 2020, and 5-year overall survival (OS) was set as the primary endpoint.

\section{Data of samples}

In this study, sex, age, smoking, family history of 


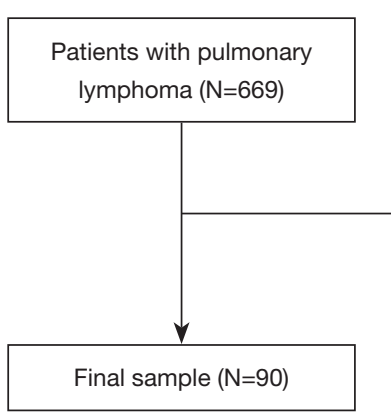

Figure 1 The flowchart of patient selection.

cancer, first symptom, ECOG performance status (PS), international performance index (IPI), CT imaging features, tumor location, histopathological results and clinical stage were included. In addition, lactate dehydrogenase (LDH) and $\beta 2$-microglobulin ( $\beta 2-M G$ ) levels were also included.

The clinical staging of patients was mainly based on Ferraro's extranodal lymphoma staging methods: stage IE: the tumor only involved the lung or bronchus (unilateral or bilateral); stage II1E: the tumor involved the lung and hilar lymph nodes; stage II2E: the tumor involved the lung and mediastinal lymph nodes; stage II2EW: the tumor involved the lung and adjacent chest wall or diaphragm; stage III: the tumor involved the lung and subphrenic lymph nodes; and stage IV: one or more extralymphatic organ or tissue was extensively involved (1).

\section{Statistical analysis}

The data in this study were analyzed by SPSS 23.0 (IBM Corp., Armonk, NY, USA) and GraphPad Prism version 8.4.3 (GraphPad Software, San Diego, CA, USA). Categorical variables were compared by Pearson's chisquare test or Fisher's exact test. The continuous variables were tested by the Mann-Whitney U test or Student's $t$-test. The survival curves were estimated by the KaplanMeier method and compared with the log rank test. A Cox regression model was used to analyze the potential factors affecting survival. Two-sided $\mathrm{P}<0.05$ was considered to indicate a significant difference.

\section{Results}

\section{Sample features}

The demographic and clinical data of all 90 patients included in the study are summarized in Table 1. Forty-

\section{Excluded:}

Secondary pulmonary lymphoma $(n=563)$

Had incomplete medical data $(n=11)$

Lost to follow-up $(n=5)$

\section{Imaging manifestations and histopathological characteristics}

Among the CT findings, 75 (83.3\%) cases of PPL involved the unilateral lobe, and the most common lesion was located at the left upper lobe (LUL). There were 12 (13.3\%) cases involving two lobes and only 3 (3.3\%) cases involving three or more lobes. All patients underwent chest CT scans, and the manifestations of PPL on CT scans were diverse.

According to Ferraro's staging of extranodal lymphoma based on Ann Arbor's lymphoma staging method, there were $24(26.7 \%)$ cases in stage IE, $16(17.8 \%)$ cases in stage II1E, 11 $(12.2 \%)$ cases in stage II2E, $10(11.1 \%)$ cases in stage II2EW, $3(3.3 \%)$ cases in stage III, and $26(28.9 \%)$ cases in stage IV. Stage II2E-IV cases in the MALT lymphoma group were fewer than in the non-MALT lymphoma group $(\mathrm{P}=0.010)$.

All patients underwent surgical resection or biopsy to obtain tumor tissue for pathological diagnosis. We found that $72.2 \%$ of PPLs were B-cell-derived lymphomas, and only one was natural killer (NK)/T-cell lymphoma. PPNHL was the most common PPL (71/90, 78.9\%). MALT lymphoma accounted for $56.3 \%$, followed by DLBCL, accounting for $32.4 \%$, and the remaining were rare pathological types.

\section{Treatment and survival}

In our series, 39 (43.3\%) patients underwent surgical 
Table 1 Clinicopathological features and treatment of 90 patients with PPL

\begin{tabular}{|c|c|}
\hline Variable & N (\%) \\
\hline \multicolumn{2}{|l|}{ Age (years) } \\
\hline Median, range & 54 [16-82] \\
\hline Mean \pm SD & $50.76 \pm 16.33$ \\
\hline Female, sex & $47(52.2 \%)$ \\
\hline Smoking history & $25(27.8 \%)$ \\
\hline Family history of tumor & $14(15.6 \%)$ \\
\hline Presenting symptoms & $68(75.6 \%)$ \\
\hline \multicolumn{2}{|l|}{ Initial symptoms } \\
\hline Cough & $35(55.6 \%)$ \\
\hline Fever & $14(22.2 \%)$ \\
\hline Bloody sputum & $7(11.1 \%)$ \\
\hline Chest pain & $27(42.8 \%)$ \\
\hline Dyspnea & $4(6.3 \%)$ \\
\hline Fatigue & $1(1.6 \%)$ \\
\hline Emaciation & $1(1.6 \%)$ \\
\hline \multicolumn{2}{|l|}{ LDH } \\
\hline Normal & $65(62.2 \%)$ \\
\hline Elevated & $25(27.8 \%)$ \\
\hline \multicolumn{2}{|l|}{$\beta 2-M G$} \\
\hline Normal & $55(61.1 \%)$ \\
\hline Elevated & $35(38.9 \%)$ \\
\hline \multicolumn{2}{|l|}{ ECOG PS } \\
\hline 0 & $24(26.7 \%)$ \\
\hline $1-2$ & $66(73.3 \%)$ \\
\hline \multicolumn{2}{|l|}{ IPI } \\
\hline $0-1$ & $30(33.3 \%)$ \\
\hline $2-5$ & $60(66.7 \%)$ \\
\hline \multicolumn{2}{|l|}{ Location of tumor } \\
\hline RUL & $19(21.1 \%)$ \\
\hline $\mathrm{RML}$ & $8(8.9 \%)$ \\
\hline RLL & $10(11.1 \%)$ \\
\hline LUL & $26(28.9 \%)$ \\
\hline LLL & $12(13.3 \%)$ \\
\hline $\mathrm{RUL}+\mathrm{RML}$ & $2(2.2 \%)$ \\
\hline RUL+RLL & $1(1.1 \%)$ \\
\hline$R U L+R M L+R L L$ & $1(1.1 \%)$ \\
\hline RUL+LUL & $1(1.1 \%)$ \\
\hline
\end{tabular}

Table 1 (continued)

\begin{tabular}{|c|c|}
\hline Variable & $\mathrm{N}(\%)$ \\
\hline $\mathrm{RML}+\mathrm{RLL}$ & $3(3.3 \%)$ \\
\hline RLL+LUL & $2(2.2 \%)$ \\
\hline RLL+LLL & $1(1.1 \%)$ \\
\hline LUL+LLL & $1(1.1 \%)$ \\
\hline $\begin{array}{l}\text { Multiple lesions of bilateral lungs } \\
\text { ( } \geq 3 \text { lobe) }\end{array}$ & $3(3.3 \%)$ \\
\hline \multicolumn{2}{|l|}{ Pathological results } \\
\hline $\mathrm{HL}$ & $19(21.1 \%)$ \\
\hline $\mathrm{CHL}$ & 19 (100.0\%) \\
\hline $\mathrm{NHL}$ & $71(78.9 \%)$ \\
\hline MALT Iymphoma & $40(56.3 \%)$ \\
\hline DLBCL & $23(32.4 \%)$ \\
\hline PTCL & $5(7.0 \%)$ \\
\hline $\mathrm{FL}$ & $1(1.4 \%)$ \\
\hline PBL & $1(1.4 \%)$ \\
\hline ENKTL & $1(1.4 \%)$ \\
\hline \multicolumn{2}{|l|}{ Clinical stage } \\
\hline IE & $24(26.7 \%)$ \\
\hline II1E & $16(17.8 \%)$ \\
\hline II2E & $11(12.2 \%)$ \\
\hline II2EW & $10(11.1 \%)$ \\
\hline III & $3(3.3 \%)$ \\
\hline IV & $26(28.9 \%)$ \\
\hline \multicolumn{2}{|l|}{ Treatment methods } \\
\hline Surgery & $24(26.7 \%)$ \\
\hline Surgery + chemotherapy & $11(12.2 \%)$ \\
\hline Surgery + radiotherapy & $2(2.2 \%)$ \\
\hline Surgery + chemoradiotherapy & $2(2.2 \%)$ \\
\hline Chemotherapy & $40(44.4 \%)$ \\
\hline Chemoradiotherapy & $11(12.2 \%)$ \\
\hline
\end{tabular}

PPL, primary pulmonary lymphoma; SD, standard deviation; $\mathrm{LDH}$, lactate dehydrogenase; $\beta 2-\mathrm{MG}, \beta 2$-microglobulin; RUL, right upper lobe; RML, right middle lobe; RLL, right lower lobe; LUL, left upper lobe; LLL, left lower lobe; HL, Hodgkin lymphoma; $\mathrm{CHL}$, classical Hodgkin lymphoma; NHL, non-Hodgkin lymphoma; MALT, mucosa-associated tissue lymphoma; DLBCL, diffuse large B-cell lymphoma; ALCL, anaplastic large cell lymphoma; LPL, lymphoplasmacytic lymphoma; PTCL, peripheral T-cell lymphoma; FL, follicular lymphoma; PBL, plasmablastic lymphoma; ENKTL, extranodal NK/T-cell lymphoma.

Table 1 (continued) 
Table 2 Clinical Characteristics and treatment of primary pulmonary MALT lymphoma and non-MALT lymphoma

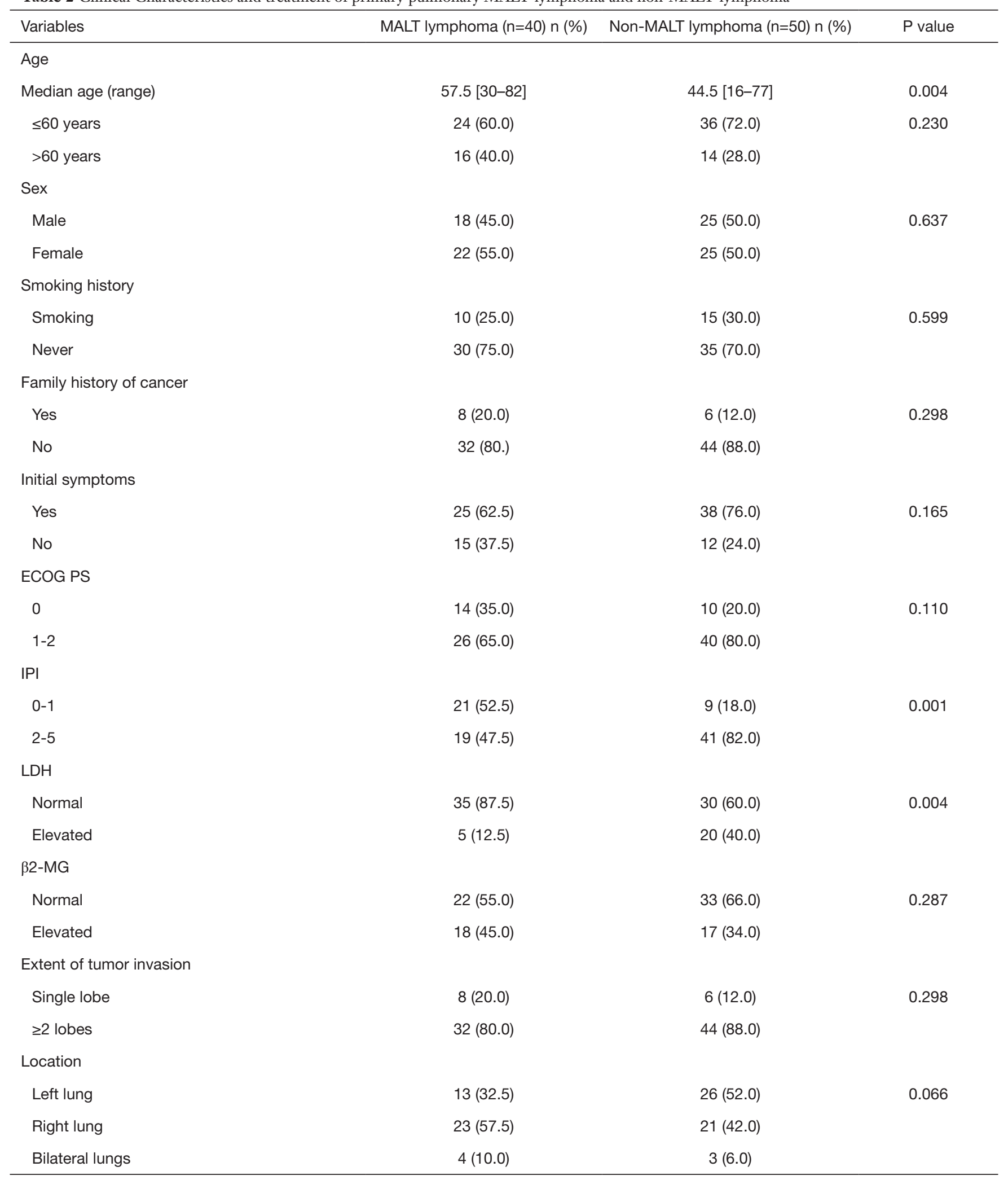

Table 2 (continued) 
Table 2 (continued)

\begin{tabular}{lcc}
\hline Variables & MALT Iymphoma $(n=40) n(\%)$ & Non-MALT lymphoma $(\mathrm{n}=50) \mathrm{n}(\%)$ \\
\hline Clinical stage & $21(52.5)$ & $13(26.0)$ \\
IE-II1E & $19(47.5)$ & $37(74.0)$ \\
II2E-IV & & $13(26.0)$ \\
Therapeutic method & $27(67.5)$ & $37(74.0)$ \\
Surgery & $13(32.5)$ & $<0.001$ \\
\hline
\end{tabular}

MALT, mucosa-associated lymphoid tissue; ECOG PS, eastern cooperative oncology group performance status; IPI, international prognostic index; LDH, lactate dehydrogenase; $\beta 2-M G, \beta 2-$ microglobulin.

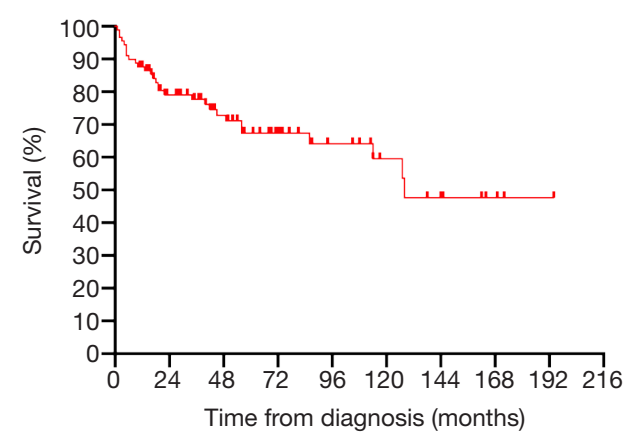

Figure 2 Overall survival curve of the whole population.

treatment, $34(87.2 \%)$ patients underwent lobectomy or combined lobectomy, $4(10.2 \%)$ patients underwent sublobectomy, and one $(2.6 \%)$ patient underwent pneumonectomy. All patients underwent mediastinal lymph node biopsy or systemic dissection at the same time. Patients with MALT lymphoma were more likely to receive surgery than those with non-MALT lymphoma $(\mathrm{P}<0.001)$. Of patients who received chemotherapy, whether adjuvant chemotherapy or direct chemotherapy, most HL patients $(14 / 18,77.8 \%)$ received the ABVD regimen (doxorubicin, bleomycin, vinblastine and dacarbazine), and the majority of NHL patients $(46 / 50,92 \%)$ received CHOP (cyclophosphamide, doxorubicin, vincristine and prednisone) or R-CHOP (rituximab+ CHOP) regimens.

All 90 patients were followed up successfully (median follow-up time was 43.5 months, ranging from 0 to 190 months). The estimated 3- and 5-year OS rates of PPL were $76.8 \%$ and $66.6 \%$, respectively (Figure 2). The estimated 5-year OS rates of MALT lymphoma and nonMALT lymphoma were $68.9 \%$ and $65.9 \%$, respectively (Figure 3). Up to the end of the follow-up, 43 (47.8\%)

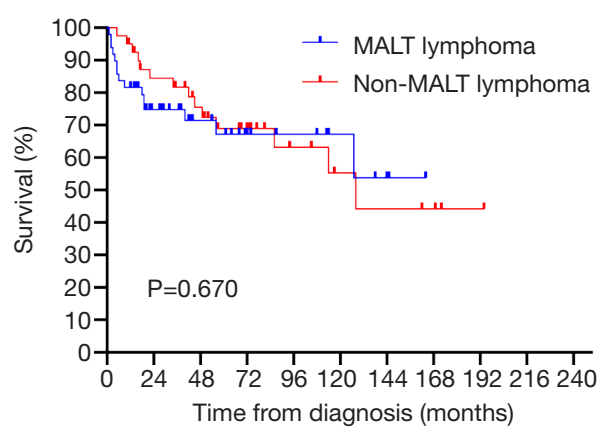

Figure 3 Comparison of overall survival between MALT lymphoma $(\mathrm{n}=40)$ and non-MALT lymphoma $(\mathrm{n}=50)$ patients. MALT, mucosa-associated lymphoid tissue.

patients survived without progression, and 17 (18.9\%) patients survived with disease progression. The remaining $30(33.3 \%)$ patients died; 24 died of disease progression or treatment-related complications, and 6 died of other causes.

\section{Prognostic factors of overall patients and subgroups}

Fourteen factors, including sex, age, smoking, family history of cancer, initial symptoms, ECOG PS score, IPI, LDH level, $\beta 2-M G$ level, extent of lobe invasion, tumor location, pathological type, clinical stage and therapeutic method, were included in the univariate Cox regression analyses (Table 3). The results showed that there were significant differences between OS and 5 factors, including age $(\mathrm{P}=0.006<0.05)$, LDH $(\mathrm{P}=0.029<0.05), \beta 2$ MG $(\mathrm{P}=0.048<0.05)$, clinical stage $(\mathrm{P}=0.015<0.05)$ and therapeutic method $(\mathrm{P}=0.046<0.05)$ (Figure 4). Subsequently, six factors with $\mathrm{P}$ values less than 0.1 were included in the multivariate analysis. Only age $(\mathrm{P}=0.013)$ could be used as an 
Table 3 Univariate and multivariate of OS in 90 cases of PPL

\begin{tabular}{|c|c|c|c|c|c|c|c|}
\hline Factors & No. (\%) & \multicolumn{3}{|c|}{ Univariate analysis } & \multicolumn{3}{|c|}{ Multivariate analysis } \\
\hline \multicolumn{8}{|l|}{ Sex } \\
\hline Male & $43(60.5)$ & Ref & & & & & \\
\hline Female & $47(72.3)$ & 0.596 & $0.288-1.230$ & 0.161 & & & \\
\hline \multicolumn{8}{|l|}{ Age } \\
\hline$\leq 60$ years old & $61(67.8)$ & Ref & & & Ref & & \\
\hline$>60$ years old & $29(32.2)$ & 2.801 & $1.352-5.801$ & 0.006 & 2.686 & $1.235-5.842$ & 0.013 \\
\hline \multicolumn{8}{|l|}{ Smoking history } \\
\hline Smoking & $25(27.8)$ & Ref & & & & & \\
\hline Yes & $14(15.6)$ & Ref & & & & & \\
\hline No & $76(84.4)$ & 0.839 & $0.318-2.210$ & 0.722 & & & \\
\hline \multicolumn{8}{|l|}{ Initial symptom } \\
\hline Yes & $68(75.6)$ & Ref & & & & & \\
\hline No & $22(24.4)$ & 0.566 & $0.214-1.499$ & 0.252 & & & \\
\hline \multicolumn{8}{|l|}{ ECOG PS } \\
\hline 0 & $24(61.5)$ & Ref & & & & & \\
\hline $1-2$ & $66(38.5)$ & 0.557 & $0.132-2.352$ & 0.426 & & & \\
\hline Normal & $65(62.5)$ & Ref & & & Ref & & \\
\hline Elevated & $25(27.8)$ & 2.26 & $1.086-4.702$ & 0.029 & 1.431 & $0.603-3.395$ & 0.416 \\
\hline \multicolumn{8}{|l|}{$\beta 2-M G$} \\
\hline Normal & $55(61.1)$ & Ref & & & Ref & & \\
\hline Elevated & 35 (38.9) & 2.062 & $1.005-4.230$ & 0.048 & 1.723 & $0.791-3.755$ & 0.171 \\
\hline \multicolumn{8}{|c|}{ Extent of tumor invasion } \\
\hline Single lobe & $76(84.4)$ & Ref & & & & & \\
\hline$\geq 2$ lobes & $14(15.6)$ & 0.551 & $0.167-1.820$ & 0.328 & & & \\
\hline \multicolumn{8}{|l|}{ Location } \\
\hline Left lung & 39 (43.3) & Ref & & & & & \\
\hline Right lung & $44(48.9)$ & 2.762 & $0.361-21.113$ & 0.328 & & & \\
\hline Bilateral lungs & $7(7.8)$ & 2.714 & $0.358-20.595$ & 0.334 & & & \\
\hline
\end{tabular}

Table 3 (continued) 
Table 3 (continued)

\begin{tabular}{|c|c|c|c|c|c|c|c|}
\hline Factors & No. (\%) & \multicolumn{3}{|c|}{ Univariate analysis } & \multicolumn{3}{|c|}{ Multivariate analysis } \\
\hline \multicolumn{8}{|l|}{ Pathological type } \\
\hline $\mathrm{HL}$ & $19(21.1)$ & Ref & & & & & \\
\hline $\mathrm{NHL}$ & 71 (78.9) & 3.006 & $0.908-9.955$ & 1.722 & & & \\
\hline MALT Iymphoma & $40(44.4)$ & Ref & & & & & \\
\hline Non-MALT Iymphoma & $50(55.6)$ & 1.169 & $0.569-2.403$ & 0.67 & & & \\
\hline \multicolumn{8}{|l|}{ Clinical stage } \\
\hline IE-II1E & $34(37.8)$ & Ref & & & Ref & & \\
\hline Surgery & $40(44.4)$ & Ref & & & Ref & & \\
\hline Non-surgery & $50(55.6)$ & 2.179 & $1.015-4.679$ & 0.046 & 1.45 & $0.562-3.740$ & 0.442 \\
\hline
\end{tabular}

OS, overall survival; PPL, primary pulmonary lymphoma; HR, hazard ratio; Cl, confidence interval; Ref, reference; ECOG PS, eastern cooperative oncology group performance status; IPI, international prognostic index; LDH, lactate dehydrogenase; $\beta 2-M G$, $\beta 2$ microglobulin; HL, Hodgkin lymphoma; NHL, non-Hodgkin lymphoma; MALT, mucosa-associated tissue lymphoma.

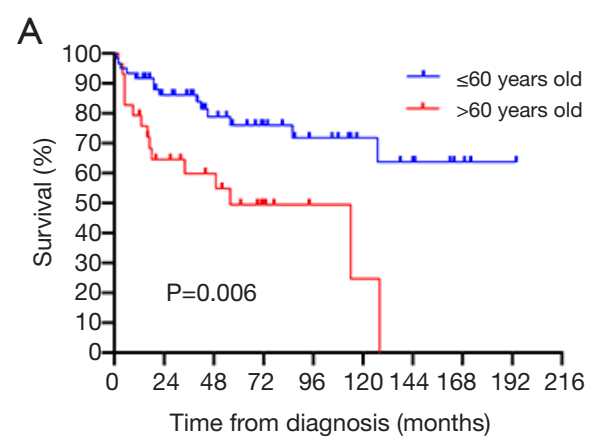

D

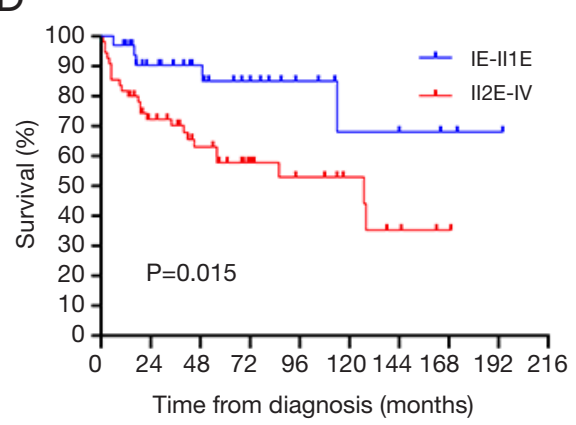

B

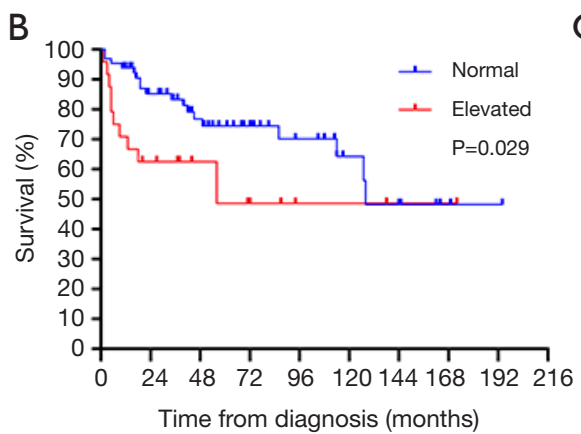

E

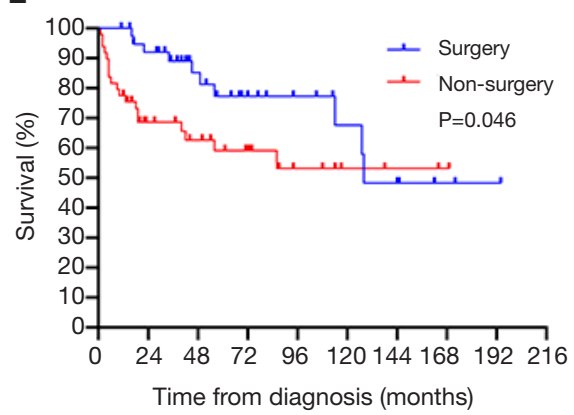

C

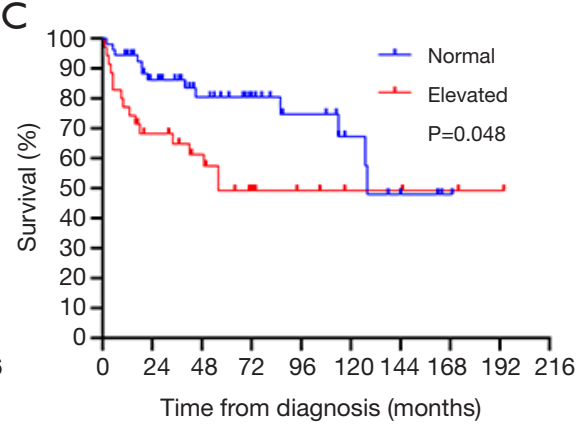

F

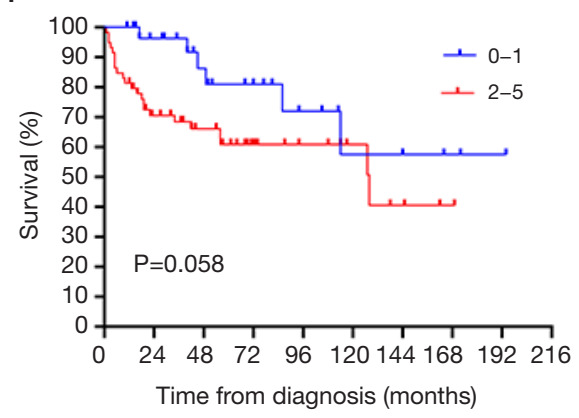

Figure 4 Comparison of overall survival rates among different groups in 90 patients with PPL: (A) age, (B) LDH level, (C) $\beta 2-M G$ level, (D) clinical stage, (E) treatment method, (F) IPI. PPL, primary pulmonary lymphoma; LDH, lactate dehydrogenase; $\beta 2-\mathrm{MG}$, $\beta 2-\mathrm{microglobulin}$. 
independent predictor for PPL patients' OS.

We also included these factors in the subgroup analysis. We found that, in the non-MALT lymphoma group, age over 60 years old $(\mathrm{P}=0.047<0.05)$, elevated $\mathrm{LDH}$ $(\mathrm{P}=0.023<0.05)$, and elevated $\beta 2-\mathrm{MG}(\mathrm{P}=0.017<0.05)$ suggested poor prognosis, but these factors, including age, could not be used as potential prognostic factors (Table S1). However, neither the univariate analysis nor the multivariate analysis showed significant differences in the survival of MALT lymphoma patients according to these factors. Therefore, no potential prognostic factor was identified (Table S2).

\section{Discussion}

Primary extranodal lymphoma mainly involves the central nervous system, gastrointestinal tract and skin, while PPL is extremely rare (15). Our study is the largest singlecenter study reported thus far, especially within the Asian population. In our study, the average age of patients was $50.76 \pm 16.33$ years old, which was consistent with the results reported in previous studies $(5,16)$. PPL was more common in middle-aged and elderly patients, and the median age at diagnosis of MALT lymphoma was older than that of nonMALT lymphoma (57.5 vs. 44.5, $\mathrm{P}=0.004)$. We found that nearly $72.0 \%$ of patients were over 40 years old, while cases in young adults and children were relatively rare $(12,17)$. There was no obvious gender preference for PPL, and the ratio of males to females was $1.1: 1$, which is similar to previous research results $(5,18,19)$. However, Brian and colleagues reported that the ratio of males to females is $1: 2$, which suggests that women are more likely to have PPL (16).

With the popularity of low-dose chest CT, a considerable number of patients have been found to have PPL during physical examination. In our case series, $24.6 \%$ of the patients did not exhibit any respiratory symptoms or systemic symptoms; their disease was found incidentally during their regular health examination, even though some patients had tumors at a late clinical stage. Ferraro et al. also found that cough was the most common symptom and that fever, chest pain, dyspnea, and hemoptysis were among the other symptoms $(1,16)$. The difference between our studies is that approximately $30.0 \%$ of their patients experienced fatigue and weight loss, and $15.0 \%$ of the patients had diaphoresis (1). In our case, only one patient had emaciation and fatigue as the first symptom, and no patient showed diaphoresis.

PPL is more likely to invade the unilateral lobe, both in our study as well as previous studies $(16,20,21)$. Up to 83.3\% of PPLs involved single lobes, of which the LUL was the most common site, which was slightly higher than the results of previous studies (61.0-68.4\%) (16,22). This may be related to our larger sample size. In addition, compared with the left side, tumor involvement on the right side was more common (48.9\% vs. $43.3 \%$ ); in Ferraro's study, the right side was also more common than the left side $(33.0 \%$ vs. $23.0 \%)(1)$.

The imaging findings of PPL are nonspecific and easily confused with common non-small cell lung cancer (NSCLC). Zhang and Albano et al. found that consolidation was the most common CT finding, followed by masses and nodules $(18,23)$. However, in our study, masses were the most common CT finding $(67.8 \%)$, with regular or irregular shapes, smooth edges or lobulated shapes, which could appear in the lung or subpleural. Single lesions were more common than multiple lesions $(51.1 \%$ vs. $7 \%)$, and consolidation and pneumonia were the other common CT findings. A previous retrospective study reported that the main imaging features of PPL were consolidation and ground-glass opacity, accompanied by bronchiectasis (14). It has also been reported that air bronchography and CT angiography in high-resolution CT (HRCT) are significantly less common in the non-MALT lymphoma group than in the MALT lymphoma group (24). However, these findings are not sufficient to help radiologists make differential diagnoses before treatment. PET-CT is rarely used as a routine examination; thus, the characteristics of PPL in PET-CT also lack research.

PPNHL accounted for $78.9 \%$ of PPL in our series, which was close to the previous report that PPL is mainly NHL (25). PPNHL is mainly B-cell lymphoma, of which MALT lymphoma is the most common. B-cell-derived MALT lymphoma is also the most common pathological type of PPL. In our study, the proportion of MALT lymphoma cases among PPL was $44.4 \%$, which was lower than the $66.6-80.0 \%$ frequency reported in earlier studies $(1,16,18)$. This may be related either to the fact that our study involved more cases than other studies or to the exclusion of patients with incomplete information and those lost to follow-up. DLBCL is the second most common PPL, accounting for $32.4 \%$ of PPNHL and $25.6 \%$ of PPL. DLBCL can be transformed from indolent MALT lymphoma to aggressive malignant lymphoma and can also occur through primary proliferation $(3,26)$. Although the proportion of DLBCL in PPL is low, it is one of the pathological types that needs active treatment because of 
its high degree of malignancy and rapid progression. T-cell lymphoma is extremely rare in the lung. In our series, there were only 5 cases of T-cell lymphoma, of which 3 were ALK-positive ALCL. ALCL is characterized by large cell anaplastic morphology, strong expression of CD30 and frequent activation of phospho-STAT3 (27). ALK expression in ALK-positive ALCL is induced by fusion of the ALK gene with different partners, of which NPM1 is the most common. ALK-positive ALCL rarely occurs in lymph nodes and extranodal tissues (28).

Surgical treatment for stage IE-II1E patients can facilitate a clear diagnosis and can also completely remove lesions with a satisfying therapeutic effect, especially for low-grade MALT lymphoma (29). In our study, $87.2 \%$ (34/39) of the patients receiving surgical treatment had MALT lymphoma and classical HL, and 70.5\% (24/34) of these patients were still alive at the end of follow-up. For PPL, surgical treatment should be recommended when imaging examination indicates that the lesion is limited and there is no distant invasion. Considering the high recurrence rate of malignant tumors in situ, complete resection of lesions can benefit patients. In our study, patients with surgical treatment had better survival benefits than patients without surgical treatment $(\mathrm{P}<0.05)$, which is consistent with previous research $(1,22,30)$. However, most PPLs were found because the lesions were not limited to one area; the lymph nodes or adjacent tissues were involved, and surgery could not completely remove the lesions to achieve effective treatment effects. In these cases, chemotherapy and radiotherapy should be recommended. For MALT lymphoma, the CHOP chemotherapy regimen has achieved good results. The advent of rituximab has been beneficial for patients with MALT lymphoma, especially CD20-positive patients. For invasive DLBCL, the R-CHOP regimen has a good effect, achieving a complete remission rate of $70-80 \%$ (31).

In our study, we found that patients aged over 60 , with elevated $\mathrm{LDH}$ and $\beta 2-\mathrm{MG}$, clinical stage II2E and greater, and patients without surgical treatment had a poor prognosis. However, smoking, PS score, tumor location and extent of involvement often affect the prognosis of patients with other tumors, but there is no significant difference in PPL, which may be related to the limited number of cases or may not truly affect the prognosis of patients. There was no significant difference in OS between primary pulmonary MALT lymphoma and non-MALT lymphoma $(\mathrm{P}=0.670>0.05)$, which corresponds to the finding reported by Ferraro et al. (1). Previous studies have found that IPI has an impact on the prognosis of lymphoma patients $(18,19)$. In our series, although there was no significant difference between IPI and OS $(\mathrm{P}=0.058)$, the trend was relatively close. $\mathrm{LDH}$ was confirmed as a risk factor for poor prognosis of NHL in early studies $(32,33)$. In our study, LDH was also a risk factor affecting the prognosis of the PPL and non-MALT lymphoma groups. The major histocompatibility complex (MHC) class I antigen is formed by noncovalent binding of $\beta 2-M G$ with heavy chain or $\alpha$. Cancer cells can evade $\mathrm{T}$-cell recognition by downregulating or completely losing MHC class I molecules (34). The structural deficiency of MHC may change the expression of epitopes and increase the expression of $\beta 2-M G$ (35). Chen et al. found that a higher level of $\beta 2-M G$ was significantly associated with greater invasion potential and tumor burden. The serum $\beta 2-M G$ level is a powerful indicator to predict the survival outcome of DLBCL (36). Zhang et al. also found that elevated $\beta 2-M G$ can be used as an independent prognostic factor for secondary pulmonary lymphoma (18). Although it was not an independent prognostic factor in our study, it was still a risk factor for the prognosis of PPL and non-MALT lymphoma groups. PPL was more common in the elderly, and age older than 60 years was significantly associated with poor prognosis, which is similar to previous studies (18). In our survival analysis, age could be used as a potential independent prognostic factor, which provides a reference for patients in the choice of treatment options.

However, there are still several limitations to our study. First, because of the inherent limitations of retrospective studies and single center research, the bias of patient selection and the limited number of patients are inevitable issues. Second, since the data included in the study were from the past 20 years, the disease-free survival (DFS) data of some patients were missing in the follow-up. Therefore, we did not analyze the relationship between the clinicopathological characteristics and the DFS of patients. Third, the number of patients in each subgroup of the nonMALT lymphoma group was very limited, and there was no deep subgroup analysis in this study. We hope that the subgroup will be further analyzed and summarized when more cases are accumulated.

\section{Conclusions}

In summary, our study further confirmed that PPL is mainly B-cell lymphoma and that MALT lymphoma is the most common pathological subtype. Most of the patients were found to have PPL due to respiratory or 
systemic symptoms, such as cough, chest tightness, fever, expectoration or chest pain. The CT imaging features of nodules or masses are not specific, and the diagnosis mainly depends on pathological results. Chemotherapy alone or combined with radiotherapy is still the main treatment for PPL, but active surgical treatment for stage IE-II1E patients can confer survival benefits. Age over 60 years old, elevated LDH and $\beta 2-\mathrm{MG}$ levels, clinical stage II2E disease or higher, and nonsurgical treatment were associated with poor prognosis. Age over 60 years old can act as a prognostic indicator of poor outcome in patients with PPL. The clinical significance of age as a prognostic indicator must be further validated.

\section{Acknowledgments}

We thank all the staff in the Department of Thoracic Surgery for their support during the study.

Funding: This study was supported by the Institutional Fundamental Research Funds (2018PT32033) and the Ministry of Education Innovation Team Development Project (IRT-17R10).

\section{Footnote}

Reporting Checklist: The authors have completed the STROBE reporting checklist. Available at http://dx.doi. org/10.21037/jtd-20-3159

Data Sharing Statement: Available at http://dx.doi. org/10.21037/jtd-20-3159

Conflicts of Interest: All authors have completed the ICMJE uniform disclosure form (available at http://dx.doi. org/10.21037/jtd-20-3159). The authors have no conflicts of interest to declare.

Ethical Statement: The authors are accountable for all aspects of the work in ensuring that questions related to the accuracy or integrity of any part of the work are appropriately investigated and resolved. The study was conducted in accordance with the Declaration of Helsinki (as revised in 2013). The study protocol was reviewed and approved by the ethics committee of the National Cancer Center/Cancer Hospital, Chinese Academy of Medical Sciences and Peking Union Medical College (approval number: 20/313-2509). The requirement for informed consent was waived because of the retrospective nature of this study.

Open Access Statement: This is an Open Access article distributed in accordance with the Creative Commons Attribution-NonCommercial-NoDerivs 4.0 International License (CC BY-NC-ND 4.0), which permits the noncommercial replication and distribution of the article with the strict proviso that no changes or edits are made and the original work is properly cited (including links to both the formal publication through the relevant DOI and the license). See: https://creativecommons.org/licenses/by-nc-nd/4.0/.

\section{References}

1. Ferraro P, Trastek VF, Adlakha H, et al. Primary nonHodgkin's lymphoma of the lung. Ann Thorac Surg 2000;69:993-7.

2. Clagett OT, Allen TH, Payne WS, et al. The Surgical Treatment of Pulmonary Neoplasms: A 10-Year Experience. J Thorac Cardiovasc Surg 1964;48:391-400.

3. Kurtin PJ, Myers JL, Adlakha H, et al. Pathologic and clinical features of primary pulmonary extranodal marginal zone B-cell lymphoma of MALT type. Am J Surg Pathol 2001;25:997-1008.

4. L'Hoste RJ Jr, Filippa DA, Lieberman PH, et al. Primary pulmonary lymphomas. A clinicopathologic analysis of 36 cases. Cancer 1984;54:1397-406.

5. Cordier JF, Chailleux E, Lauque D, et al. Primary pulmonary lymphomas. A clinical study of 70 cases in nonimmunocompromised patients. Chest 1993;103:201-8.

6. Restrepo CS, Carrillo J, Rosado de Christenson M, et al. Lymphoproliferative lung disorders: a radiologicpathologic overview. Part II: Neoplastic disorders. Semin Ultrasound CT MR 2013;34:535-49.

7. Zinzani PL, Martelli M, Poletti V, et al. Practice guidelines for the management of extranodal non-Hodgkin's lymphomas of adult non-immunodeficient patients. Part I: primary lung and mediastinal lymphomas. A project of the Italian Society of Hematology, the Italian Society of Experimental Hematology and the Italian Group for Bone Marrow Transplantation. Haematologica 2008;93:1364-71.

8. Seeram V, Shujaat A, Jones L, et al. An 82-year-old woman with left upper lobe atelectasis. Diffuse large B-cell lymphoma. Chest 2012;142:1669-74.

9. Shahani L, McKenna M. Primary pulmonary lymphoma in a patient with advanced AIDS. BMJ Case Rep 2014;2014.

10. Hare SS, Souza CA, Bain G, et al. The radiological spectrum of pulmonary lymphoproliferative disease. $\mathrm{Br} \mathrm{J}$ Radiol 2012;85:848-64. 
11. Balbo-Mussetto A, Saviolo C, Fornari A, et al. Whole body MRI with qualitative and quantitative analysis of DWI for assessment of bone marrow involvement in lymphoma. Radiol Med 2017;122:623-32.

12. Pina-Oviedo S, Weissferdt A, Kalhor N, et al. Primary Pulmonary Lymphomas. Adv Anat Pathol 2015;22:355-75.

13. Begueret H, Vergier B, Parrens M, et al. Primary Lung Small B-Cell Lymphoma versus Lymphoid Hyperplasia: Evaluation of Diagnostic Criteria in 26 Cases. Am J Surg Pathol 2002;26:76-81.

14. Cozzi D, Dini C, Mungai F, et al. Primary pulmonary lymphoma: imaging findings in 30 cases. Radiol Med 2019;124:1262-9.

15. Zucca E, Cavalli F. Extranodal lymphomas. Ann Oncol 2000;11 Suppl 3:219-22.

16. Graham BB, Mathisen DJ, Mark EJ, et al. Primary pulmonary lymphoma. Ann Thorac Surg 2005;80:1248-53.

17. Wu X, Zhou C, Jin L, et al. Primary pulmonary lymphoma in children. Orphanet J Rare Dis 2019;14:35.

18. Zhang MC, Zhou M, Song Q, et al. Clinical features and outcomes of pulmonary lymphoma: A single center experience of 180 cases. Lung Cancer 2019;132:39-44.

19. Zhang XY, Gu DM, Guo JJ, et al. Primary Pulmonary Lymphoma: A Retrospective Analysis of 27 Cases in a Single Tertiary Hospital. Am J Med Sci 2019;357:316-22.

20. Hu YH, Hsiao LT, Yang CF, et al. Prognostic factors of Chinese patients with primary pulmonary non-Hodgkin's lymphoma: the single-institute experience in Taiwan. Ann Hematol 2009;88:839-46.

21. Low SK, Zayan AH, Istanbuly O, et al. Prognostic factors and nomogram for survival prediction in patients with primary pulmonary lymphoma: a SEER population-based study. Leuk Lymphoma 2019;60:3406-16.

22. Yao D, Zhang L, Wu PL, et al. Clinical and misdiagnosed analysis of primary pulmonary lymphoma: a retrospective study. BMC Cancer 2018;18:281.

23. Albano D, Borghesi A, Bosio G, et al. Pulmonary mucosaassociated lymphoid tissue lymphoma: (18)F-FDG PET/CT and CT findings in 28 patients. Br J Radiol 2017;90:20170311.

24. Chen Y, Chen A, Jiang H, et al. HRCT in primary pulmonary lymphoma: can CT imaging phenotypes differentiate histological subtypes between mucosaassociated lymphoid tissue (MALT) lymphoma and nonMALT lymphoma? J Thorac Dis 2018;10:6040-9.

25. Parissis H. Forty years literature review of primary lung lymphoma. J Cardiothorac Surg 2011;6:23.

26. Deutsch AJ, Aigelsreiter A, Staber PB, et al. MALT lymphoma and extranodal diffuse large B-cell lymphoma are targeted by aberrant somatic hypermutation. Blood 2007;109:3500-4.

27. Beltran Beltran S, de Tomas Labat ME, Ferreras Fernandez P. Primary Ki-1 positive anaplastic large cell non-Hodgkin's lymphoma of the lung. A case study and review of the literature. An Med Interna 2001;18:587-90.

28. Lemonnier F, Gaulard P, de Leval L. New insights in the pathogenesis of T-cell lymphomas. Curr Opin Oncol 2018;30:277-84.

29. Ahmed S, Kussick SJ, Siddiqui AK, et al. Bronchialassociated lymphoid tissue lymphoma: a clinical study of a rare disease. Eur J Cancer 2004;40:1320-6.

30. Vanden Eynden F, Fadel E, de Perrot M, et al. Role of surgery in the treatment of primary pulmonary B-cell lymphoma. Ann Thorac Surg 2007;83:236-40.

31. Pfreundschuh M, Trumper L, Osterborg A, et al. CHOP-like chemotherapy plus rituximab versus CHOPlike chemotherapy alone in young patients with goodprognosis diffuse large-B-cell lymphoma: a randomised controlled trial by the MabThera International Trial (MInT) Group. Lancet Oncol 2006;7:379-91.

32. Yi JH, Kim JH, Baek KK, et al. Elevated LDH and paranasal sinus involvement are risk factors for central nervous system involvement in patients with peripheral T-cell lymphoma. Ann Oncol 2011;22:1636-43.

33. Liu YZ, Luo P, Liu C, et al. Prognostic Significance of LDH Ratio in Serum/Cerebral Spinal Fluid of Patients with Primary Testicular Diffuse Large B-Cell Lymphoma. Onco Targets Ther 2019;12:10469-75.

34. Vinay DS, Ryan EP, Pawelec G, et al. Immune evasion in cancer: Mechanistic basis and therapeutic strategies. Semin Cancer Biol 2015;35 Suppl:S185-S98.

35. Ferrier P, Layet C, Caillol DH, et al. The association between murine beta 2-microglobulin and HLA class I heavy chains results in serologically detectable conformational changes of both chains. J Immunol 1985;135:1281-7.

36. Chen Y, Neelapu S, Feng L, et al. Prognostic significance of baseline peripheral absolute neutrophil, monocyte and serum beta2-microglobulin level in patients with diffuse large b-cell lymphoma: a new prognostic model. Br J Haematol 2016;175:290-9.

Cite this article as: He H, Tan F, Xue Q, Liu L, Peng Y, Bai G, Zhang M, Gao S. Clinicopathological characteristics and prognostic factors of primary pulmonary lymphoma. J Thorac Dis 2021;13(2):1106-1117. doi: 10.21037/jtd-20-3159 
Supplementary

Table S1 Univariate and multivariate analyses of OS in 50 cases of non-MALT lymphoma

\begin{tabular}{|c|c|c|c|c|c|c|c|}
\hline \multirow{2}{*}{ Factors } & \multirow{2}{*}{ No. (\%) } & \multicolumn{3}{|c|}{ Univariate analysis } & \multicolumn{3}{|c|}{ Multivariate analysis } \\
\hline & & $\mathrm{HR}$ & $95 \% \mathrm{Cl}$ & P-value & $\mathrm{HR}$ & $95 \% \mathrm{Cl}$ & $P$ value \\
\hline \multicolumn{8}{|l|}{ Sex } \\
\hline Male & $25(50.0)$ & Ref & & & & & \\
\hline Female & $25(50.0)$ & 0.724 & $0.269-1.950$ & 0.523 & & & \\
\hline \multicolumn{8}{|l|}{ Age } \\
\hline$\leq 60$ years old & $36(72.0)$ & Ref & & & Ref & & \\
\hline$>60$ years old & 14(28.0) & 2.83 & $1.014-7.897$ & 0.047 & 1.427 & $0.441-4.617$ & 0.553 \\
\hline \multicolumn{8}{|l|}{ Smoking history } \\
\hline Smoking & $15(30.0)$ & Ref & & & & & \\
\hline Never & $35(70.0)$ & 1.017 & $0.352-2.935$ & 0.976 & & & \\
\hline \multicolumn{8}{|c|}{ Family history of cancer } \\
\hline Yes & $6(12.0)$ & Ref & & & & & \\
\hline No & $44(88.0)$ & 1.104 & $0.249-4.885$ & 0.897 & & & \\
\hline \multicolumn{8}{|l|}{ Initial symptom } \\
\hline Yes & $43(86.0)$ & Ref & & & & & \\
\hline No & $7(17.0)$ & 0.992 & $0.225-4.377$ & 0.991 & & & \\
\hline \multicolumn{8}{|l|}{ ECOG PS } \\
\hline 0 & $10(20.0)$ & Ref & & & & & \\
\hline $1-2$ & $40(80.0)$ & 1.581 & $0.359-6.961$ & 0.544 & & & \\
\hline \multicolumn{8}{|l|}{ IPI } \\
\hline $0-1$ & $9(18.0)$ & Ref & & & & & \\
\hline $2-5$ & $41(82.0)$ & 4.205 & $0.552-32.059$ & 0.166 & & & \\
\hline \multicolumn{8}{|l|}{$\mathrm{LDH}$} \\
\hline Normal & $30(60.0)$ & Ref & & & Ref & & \\
\hline Elevated & $20(40.0)$ & 3.257 & $1.175-9.026$ & 0.023 & 2.294 & $0.746-7.054$ & 0.148 \\
\hline \multicolumn{8}{|l|}{$\beta 2-\mathrm{MG}$} \\
\hline Normal & $33(66.0)$ & & & & Ref & & \\
\hline Elevated & $17(34.0)$ & 3.357 & $1.242-9.074$ & 0.017 & 2.328 & $0.766-7.076$ & 0.136 \\
\hline \multicolumn{8}{|c|}{ Extent of tumor invasion } \\
\hline Single lobe & $6(12.0)$ & Ref & & & & & \\
\hline$\geq 2$ lobes & $44(88.0)$ & 26.089 & $0.054-12587.107$ & 0.301 & & & \\
\hline \multicolumn{8}{|l|}{ Location } \\
\hline Left lung & $26(52.0)$ & Ref & & & & & \\
\hline Right lung & $21(42.0)$ & 1.086 & $0.402-2.938$ & 0.871 & & & \\
\hline Bilateral lungs & $3(6.0)$ & 0 & $0.000-0.000$ & 0.983 & & & \\
\hline \multicolumn{8}{|l|}{ Clinical stage } \\
\hline IE-II1E & 13(26.0) & Ref & & & & & \\
\hline II2E-IV & $37(74.0)$ & 6.176 & $0.814-46.830$ & 0.078 & & & \\
\hline \multicolumn{8}{|c|}{ Therapeutic method } \\
\hline Surgery & $13(26.0)$ & Ref & & & & & \\
\hline Non-surgery & $37(74.0)$ & 7.539 & $0.982-57.851$ & 0.052 & & & \\
\hline
\end{tabular}

OS, overall survival; MALT, mucosa-associated lymphoid tissue; HR, hazard ratio; $\mathrm{Cl}$, confidence interval; Ref, reference; ECOG PS, eastern cooperative oncology group performance status; IPI, international prognostic index; LDH, lactate dehydrogenase; $\beta 2-\mathrm{MG}, \beta 2-$ microglobulin. 
Table S2 Univariate and multivariate analyses of OS in 40 cases of MALT lymphoma

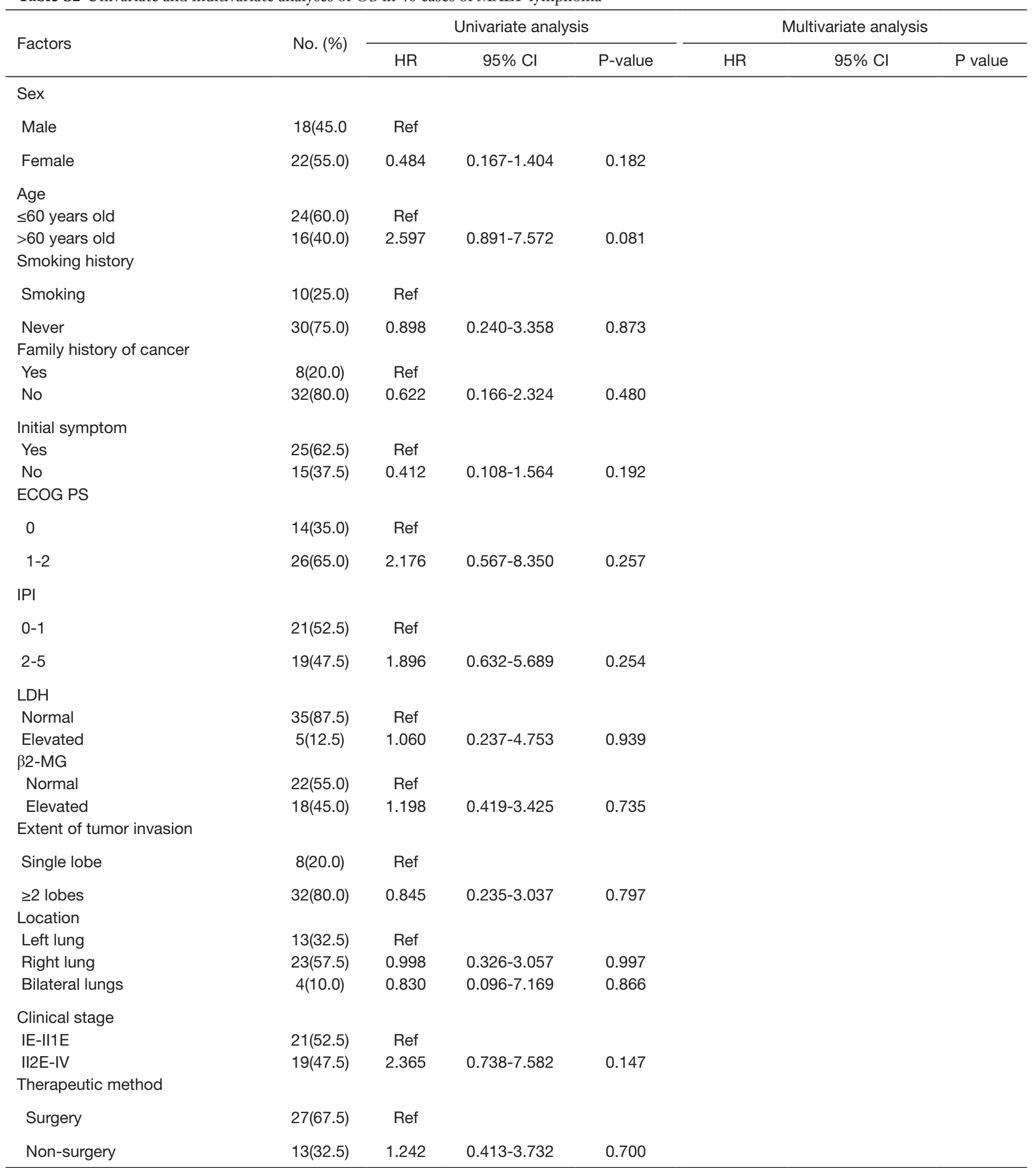

OS, overall survival; MALT, mucosa-associated lymphoid tissue; HR, hazard ratio; CI, confidence interval; Ref, reference; ECOG PS, eastern cooperative oncology group performance status; IPI, international prognostic index; LDH, lactate dehydrogenase; $\beta 2-\mathrm{MG}$, $\beta 2$ microglobulin. 